\title{
The comparison of Nice knots and traditional methods as an auxiliary reduction-fixation technique in pre-contoured locking plate fixation for comminuted Robinson type 2B clavicle fracture: a retrospective study
}

\section{Shengkun Hong}

Department of Orthopaedic Surgery, Quzhou People's Hospital

\section{Wei Wang}

Department of Orthopaedic Surgery, Quzhou People's Hospital

Jinku Guo

Department of Orthopaedic Surgery, Quzhou People's Hospital

\section{Feixiong $\mathrm{He}$}

Department of Orthopaedic Surgery, Quzhou People's Hospital

\section{Cong Wang (D 05wangcong@zju.edu.cn )}

Department of Orthopaedic Surgery, the Second Affiliated Hospital, Zhejiang University School of Medicine

\section{Research article}

Keywords: midshaft clavicle fracture, pre-contoured locking plate, Nice knot, lag screw, wire, operation time, healing time, nonunion, refracture

Posted Date: June 8th, 2020

DOl: https://doi.org/10.21203/rs.3.rs-33348/v1

License: (c) (1) This work is licensed under a Creative Commons Attribution 4.0 International License. Read Full License

Version of Record: A version of this preprint was published at Medicine on June 11th, 2021. See the published version at https://doi.org/10.1097/MD.0000000000026282. 


\section{Abstract}

Background: Open reduction and pre-contoured locking plate fixation is a popular treatment option for displaced midshaft clavicle fracture. Lag screw and cerclage are two main intraoperative techniques to reduce and fix fragments. However, both lag screw and metallic cerclage have disadvantages. The doubled-suture Nice knot has been reported in many areas of orthopedic surgery for its effectiveness. This study aims to compare the outcomes of comminuted mid-shaft clavicle fractures reduced by Nice knots versus traditional techniques (lag screw or/and metallic cerclage) when bridged with pre-contoured locking plates.

Methods: We retrospectively reviewed 101 patients (65 females and 36 males) diagnosed with midshaft clavicle fractures with at least one wedge fragment reduced by either Nice knots or traditional methods and bridged with pre-contoured locking plates between December 2016 and April 2019. Operation time, functional outcomes, pain, patient satisfaction, fracture healing and complications were assessed at a follow-up of 12 to 40 months.

Results: The mean age of all the patients was 50.8 years. There were 52 and 49 patients in Nice knot group and traditional group respectively, and no differences between two groups was found in general patient characteristics, fracture type, follow up and injury-to-surgery duration. The Nice knot group had significant less operation time $(p<0.01)$ than the traditional group (mean and standard deviation [SD], $78.6 \pm 19.0$ compared with $94.4 \pm 29.9$ minutes, respectively). For healing time, functional score, pain, satisfaction and complications, there was no significant differences between groups, despite the Nice knot group had slightly better results.

Conclusions: Both Nice knots and traditional methods treated for comminuted Robinson type 2B clavicle fractures were effective and safe. And the Nice knots seemed to be superior with significant less operation time.

\section{Introduction}

Clavicle fracture is very common injury, comprising $35-44 \%$ of all injuries to the shoulder girdle and 2.6$4 \%$ of all fractures in adults [1,2]. It happens mostly in young people and the most dominant causes are vehicle accidents and falls, either on flat or from high, account for $91.0 \%$ of all the clavicle fractures in China [3]. $69.2 \%$ of clavicle fractures involve the intermediate three-fifths of the diaphysis classified as Type- 2 by Robinson in 1998, and the most common was displaced fracture (Type 2B), especially with wedge comminution or comminuted segments, which associated with an increased risk of delayed union or nonunion [4]. Traditionally, nonoperative therapy was thought to be effective method for most displaced clavicle fractures [2,5]. However, recent studies demonstrated lower rates of complications, faster healing process and higher functional scores in groups treated operatively compared with nonoperatively [6, 7]. Patients suffered from clavicle fracture with significant displacement, potential open or open fractures, neurovascular compromise, pathological fractures, polytrauma, floating shoulder 
may require surgical treatment [2]. Therefore, surgical interventions have obviously increased for displaced midshaft clavicle fractures in the last decades [8].

For operative treatment, open reduction and internal fixation (ORIF) with plates or intramedullary fixation is still the most popular choice $[9,10]$. Compared with intramedullary nails, the pre-contoured locking plate is still considered the first choice for comminuted midshaft clavicle factures because of its firm anatomical reduction and shorter term to return activity $[7,9,11]$. It is also widely accepted that adequate reduction is necessary for achieving stable fixation if possible and is good for reducing the risk of complications like fixation failure and nonunion, which is more common in comminuted midshaft clavicle fractures. In open reduction, there are two main intraoperative techniques to reduce and fix single wedged or comminuted fragments of clavicle fractures. Lag screw seems to be standard method when the fragments are big enough, and cerclage is usually applicated when the fragments is too small for screw drilling [12]. But fragmentation or devitalization results from trying to set a lag screw is not rare [13], which may be associated with delay union even nonunion. And cerclage of fragments is also not easy without preliminary reduction and temporary fixation.

Recent studies compared the metallic and non-metallic cerclage and advocated using the latter to treat various fractures [13-15]. The doubled-suture Nice knot, characterized as sliding, self-stabilizing, adjustable, easy to perform and solid, is used increasingly in many types of orthopedic surgery nowadays [13]. But the literatures about application and result of Nice knot as an auxiliary reduction technique in ORIF of comminuted Type 2B midshaft clavicle fractures is rare. Therefore, the aim of this study is to evaluate the intraoperative effectiveness, short term clinical outcomes, radiological outcomes and complications of comminuted Type 2B clavicular shaft fractures reduced by Nice knots compared with traditional techniques when bridged with pre-contoured locking plates.

\section{Methods}

This is a retrospective study, conducted after obtaining institutional ethical committee clearance. We reviewed all the 207 inpatient clavicle fractures between December 2016 and April 2019 in our database, and 41 patients with distal or medial end fractures, 35 patients with simple midshaft fractures (without wedge fragment), 21 patients treated nonoperatively were excluded. Of the left 110 patients with wedge fragments, 8 patients were excluded due to the use of reconstruction plates. Finally, 102 patients met the inclusion criteria of midshaft clavicle fractures with at least one wedge fragment reduced by either Nice knots or traditional methods and bridged with pre-contoured locking plates. One patient was lost during follow-up. The rest 101 patients completed minimum of 12 months' follow-up (Table 1). All fractures were closed and fracture morphology was assessed by X-ray and/or CT and confirmed intraoperatively. Figure 1 is the patient flow chart. 
Table 1

Patient characteristic and surgical data

\begin{tabular}{|c|c|c|c|}
\hline & $\begin{array}{l}\text { Nice knot group } \\
(n=52)\end{array}$ & $\begin{array}{l}\text { Traditional group } \\
(n=49)\end{array}$ & $\mathbf{P}$ \\
\hline Age (years) & $50.8 \pm 11.2(24-69)$ & $50.9 \pm 12.2(20-71)$ & 0.775 \\
\hline Sex, male/female & $34 / 18$ & $31 / 18$ & 0.824 \\
\hline Left/right shoulder & $25 / 27$ & $28 / 21$ & 0.362 \\
\hline Type 2B2 & $39(75.0 \%)$ & $28(57.1 \%)$ & 0.058 \\
\hline Mechanism of injury & & & 0.947 \\
\hline Traffic accident & $31(59.6 \%)$ & $27(55.1 \%)$ & \\
\hline Fall flat & $17(32.7 \%)$ & $18(36.7 \%)$ & \\
\hline Fall from height & $3(5.8 \%)$ & $3(6.1 \%)$ & \\
\hline Sports & $1(1.9 \%)$ & $1(2.0 \%)$ & \\
\hline Injury-to-surgery (days) & $3.3 \pm 3.5(1-16)$ & $4.1 \pm 4.1(0-22)$ & 0.267 \\
\hline Plate bending & $14(26.9 \%)$ & $13(26.5 \%)$ & 0.964 \\
\hline Operation time (min) & $\begin{array}{l}78.6 \pm 19.0(40- \\
135)\end{array}$ & $\begin{array}{l}94.4 \pm 29.9(45- \\
165)\end{array}$ & 0.002 \\
\hline Follow-up (months) & $25.8 \pm 7.9(13-40)$ & $25.9 \pm 8.4(12-40)$ & 0.911 \\
\hline Implant removal & $23(44.2 \%)$ & $24(49.0 \%)$ & 0.633 \\
\hline $\begin{array}{l}\text { Interval between fixation and removal } \\
\text { (months) }\end{array}$ & $15.0 \pm 3.0(11-22)$ & $15.3 \pm 3.9(12-24)$ & 0.698 \\
\hline
\end{tabular}

Surgical process

All the surgeries were performed by skilled surgeons with more than 5 years' experience in fracture ORIF, and mostly were performed within 4 days after injuries. Every patient obtained prophylactic antibiotics with separated single-shot cephalosporin 30 min before and $24 \mathrm{~h}$ after surgery. After general anesthesia or side cervical plexus block anesthesia, patients were set in a beach-chair position or supine position with suffered shoulder elevated by thin cushion. Transverse supra-clavicular incision was used in all cases, and supraclavicular nerve was identified and protected if possible. After the subcutaneous soft tissue of superior clavicle surface was stripped, the fracture ends and wedge fragments were exposed and debrided carefully, avoid unnecessary damage of the soft tissue attached. The intraoperative methods were chosen according to surgeon preference and the figure of fragments. 
Reduction and fixation technique

Nice knot group: In the early stage, we used absorbable sutures to perform Nice knots, which were considered not strong enough by our surgeons. Recently, we used nonabsorbable sutures (eg, No. 5 Ethibond [Ethicon, Somerville, New Jersey]) to enhance the strength. Step 1: The wedge fragments were firstly pre-reduced (placed near the normal position by gentle flipping, or attached the fracture end it belongs to), so we could position the best cerclage. Step 2: At least two doubled-suture were introduced around the fragments by the tail of needle (Fig. 2). Step 3: We performed the step1 again and the Nice knots were sequentially tightened in a sliding and self-stabilizing fashion around the fracture, meanwhile the fragments could be adjusted and further reduced by clamps. If it was big enough, the wedge fragment could be temporary fixed with 1.0 or 1.5 Kirschner wire to easy the operating. Step 4: Following the Nice knots definitively tightened anterior, the pre-contoured locking plate (Trauson, China or Sanatmetal, Hungary; according to the choice of patients) was fixed superior, with at least 3 screws bi-cortically placed on each side of the fracture (Fig. 3). Sometimes we had to bend the plates slightly to fit the different figure of clavicles. The position of fixation and reduction of fracture were confirmed by intraoperative C-arm X-ray. After irrigation, we closed the incision without drain. No patient had cancellous graft in this group.

Traditional group: when the size of the wedge fragment was available, lag screw was used following reduction of fracture by clamps (Fig. 4). Otherwise, the steel wire cerclage was used before the fixation of plate. The wire was introduced by vascular forceps, and tightened on the anterior surface of clavicle. The plate fixation and wound closure were performed following the same principle in Nice knot group. There was also no bone-graft in the group.

Postoperative management

All fractures were protected by arm sling for 2 weeks after operation. Passive movement for the first 2 weeks and active movement without weight-bearing begun from the third week was recommended. The range of motion (ROM) of shoulder was restricted no more than 90 degrees until 6 weeks, when most patients had finished their first follow up. Once the surgeon confirmed the safety, free ROM and tolerated weight bearing was allowed. Back to manual work and strenuous sports were not allowed until complete fracture healing. But nonmanual work was allowed if the patient could tolerate pain without weight.

All the patients were planned follow up for at least 12 months. They were called to outpatient department by telephone every 4-6weeks post-surgery for clinical and radiological exams. Once consolidation of fracture was achieved, no more asymptomatic follow-up was planned until 12 months, when a detail questionnaire was filled including functional outcomes (The Disabilities of Arm, Shoulder and Hand Score, DASH score) [16], complications, visual analog scale (VAS) and satisfaction. Hardware removal was not considered to be a complication because most patients asked for removal to deal with traffic accident compensation or they just wanted to remove even without discomfort. Any hardware failure and post-removal refracture was recorded. 


\section{Statistical analysis}

All data analysis is based on the statistical software SPSS 25.0. Surgery time and healing time were analyzed using the independent sample t-test for within-group comparisons. DASH score and VAS were analyzed using the Mann-Whitney U test for between-group comparisons. Categorical variables were compared using chi-square test or Fisher exact test to compare differences between groups. The level of significance for all tests was set at $p<0.05$.

\section{Result}

102 patients with comminute clavicle fractures of Robinson 2B treated with the pre-contoured locking plates met the inclusion criteria, and 1 patient was excluded due to loss of visit. 52 of the 101 fractures were reduced and temporarily stabilized by double-suture Nice knot, 36 patients by lag screw, 12 by steel wire, and 1 by screw combined with wire. There were 65 females and 36 males with a mean age of 50.8 when injured. $52.5 \%$ patients suffered from the left clavicle fractures, and $47.5 \%$ the right. The most common cause was traffic accident (57.4\%), then fall flat (34.7\%) and fall from height (5.9\%). Multiple injuries with chest trauma (mainly rib fractures), scapular fracture, and brain injury occurred in $41.6 \%$, $5.9 \%$, and $9.9 \%$ respectively. The classification of the fractures was estimated by X-Ray or CT scan preoperation and confirmed by review of the operative record, which indicated that the incidence of type 2B2 fractures in Nice knot group was much higher than that in tradition group but without statistical significance, $75.0 \%$ vs $57.1 \%$ ( $P=0.058$ ). The mean follow-up period was 25.9 months (range $12-40$, SD 8.1). There was no significant difference between two groups in gender, age, injury cause, fracture type, follow-up duration and injury-to-surgery duration (Table 1).

Intraoperative effectiveness

The Nice knot group costed significant less surgical time than traditional group (78.6 \pm 19.0 compared with $94.4 \pm 29.9$ minutes; $\mathrm{P}<0.01$ ) (Table 1 ). The traditional group had a slightly lower rate of intraoperative plate bending to fit the reduced clavicle but with no statistic significant $(26.5 \%$ vs $26.9 \%$, $\mathrm{P}>0.05$ ) (Table 1). In 4 cases of the traditional group surgeons record the crash of wedge fragments when screwing, one of which was reinforced by wire. Almost all the surgeons approved that additional periosteal stripping was nearly unnecessary when performed Nice knots, but always needed when lag screwing.

\section{Clinical and radiological outcomes}

X-ray and/or CT scan were performed on the day of injury. Regular X-ray examinations were performed before discharge and during the follow up. There were 41 patients showed consolidation after an average of 13.8 weeks, 1 patient had plate rupture 7 months after surgery when sleeping, another patient had plate deformation due to traffic accident 12 months post operation, and the remaining 58 patients failed to provide the information of radiographic consolidation because of no further asymptomatic radiological follow-up during from 6 weeks to 12 months post operation. The mean healing time of the 
Nice knot group was insignificantly shorter than the traditional group (13.14 \pm 3.72 compared with 14.43 \pm 2.98 weeks; $P=0.228$ ) (Table 2). At 12 months follow up, 43 patients came to take $X$-ray or CT scan and finished the questionnaires, so that some data had to been collected by a phone call for the rest participants. Completely union was observed in all the patients (76 were both radiographic and clinical healed, the rest 25 were only clinical healed due to the absent of necessary data) of both groups except the implant failure described above.

The Nice knot group had an equal DASH score and VAS score compared to the traditional group at 12th month $(p>0.05)$. Most patients were satisfactory with the final function when compared to the normal shoulder in both groups at the last visit. (Table 2)

23(44.2\%) patients removed the implants at the mean of 15.0 months in the Nice knot group, and 24(49.0\%) patients at 15.3 months in the traditional group (Table 1). Only 7(14.9\%) of these 47 patients complained skin irritation. The most common reason $(29,61.7 \%)$ was to deal with the traffic accident compensation, then the simple will $(11,23.4 \%)$ to remove even without discomfort. And 23 in the rest 54 patients expressed the willing to remove implants, of whom 5 people complained plate discomfort.

\section{Complications and revisions}

Totally, 5 patients complained numbness in the shoulder or chest aera, 2(3.8\%) and 3(6.1\%) in Nice knot group and traditional group respectively, with no significant difference $(p>0.05)$. All the incisions had good completely healing without any wound complication. (Table 2)

The plate rupture in the Nice knot group occurred at 7 months, and persistent pain in fracture area after surgery was complained by the 49 years old male patient (Fig.4). It happened during sleep when he turned over on the affected side. We also found that the surgeon turned to fix with suture owing to unsatisfactory result of lag screw and wire in this case. A revision surgery was performed by the same surgeon, using combination of anatomic and mini plate, with auto cancellous bone graft. At 15 weeks follow-up, CT scan proved the full callus growth and the patients confirmed pain-free movement.

Two patients with lag screws in the traditional group had severe complications. The 21 years old female patient suffered from refracture 2 months after implant remove when she waved inadvertently. It was treated conservatively with sling because of only slight angulation, and without no further problems in follow up. Another 20 years old male patient had a traffic accident 12 months post operation, which made the plate and clavicle deformed at the point of original fracture region. We reviewed all the radiographic and clinical data of this case, and the nonunion was confirmed. But no further surgical treatment was taken, and the patient still complained moderate pain when weighting 10 months later.

For the patients reduced single using Nice knots, the rate of major complication (nonunion or refracture) was insignificantly lower than traditional group ( $0 \%$ vs $4.1 \%, \mathrm{P}=0.233$ ).

\section{Discussion}


Traditionally, most clavicle fractures were cured conservatively. However, lower nonunion incidence and better short-term functional recovery of surgical management made surgery mainstream gradually $[9,17$, 18]. Of two main options for fixation, a plate-screw system is still considered "gold standard" for comminuted midshaft clavicle facture, other than an intramedullary nail $[9,7,11]$. Lag screw, cerclage wire, and suture were widely used in ORIF of comminuted clavicle factures with good clinical outcomes, but which is better was not clear. To our knowledge, it was the very first study comparing a special suture knot with lag screw or cerclage wire for the treatment of midshaft clavicle fractures. The aim of the current study was to screen an easily performed, auxiliary reduction technique that may simplify reduction of displaced comminuted clavicle fractures meanwhile achieving acceptable clinical outcomes. The result of the current study indicated that the Nice knot group was associated with significant less operation time, slightly quicker healing progress and insignificant lower complication rate.

The Nice knots were widely applicated in variety orthopedic surgery over the past decade, especially humeral tuberosity fractures and arthroscopy $[13,19]$. This special knot is characterized as sliding, selfstabilizing, easy to perform, adjustable and solid [13]. For a skilled surgeon, reduction of free fragments could be extremely simple, just by gentle flipping, and temporary fixation could be performed at the same time when tightening the knots. Additionally, in this study we used a modified method to introduce the double-suture by the tail of suture needle which could simplify the process and was considered safer to decrease neurovascular injuries, as the tail is blunt than the pinhead. Contrary, to fix a wedge fragment by a lag screw required reduction first by clamp and holding on during drilling and screwing in. But it is not always easy to achieve and maintain an anatomic fracture reduction, particularly the multi-fragments were tiny. Fragmentation or devitalization of fracture was also extremely common during screwing. Cerclage is theoretically a simple technique, but sometimes it is very challenging to achieve a satisfactory result. Simple wires can break during twisting, the tension applied is often subjective, common surgical node can slip, clamps can lose grip and so on. Moreover, wires were closed with a twist, which can weaken the fixation strengthen, proved by Wahnert et al [20] in their biomechanical study. All the disadvantages described above might increase operation time in the traditional group. Importantly, the mean operation time of the Nice knot group in the current study $(78.56 \mathrm{~min})$ was even less than some previous reports(70-100 min) of open plating for midshaft clavicle fractures [21, 22, 23]. Additionally, the proportion of Type 2B2 fractures was significantly higher in the Nice knot group, which seemed to hint that the method is more suitable for this type of complicated fractures.

In our study, the mean healing time was 13.8 weeks for 41 patients, it was comparable to the literatures (range 12-16.5 weeks) of whether minimally invasive plate osteosynthesis (MIPO) or conventional open plating $[24,25,26]$. And the fractures seemed to heal faster in the Nice group than traditional group, this is not surprising for two reasons: First, the very important factor for bone regeneration are the periosteum and blood supply, which could be even completely retained when making Nice knots by our skilled surgeons. However, placing lag screws almost always needed additional periosteal stripping to show enough space to perform. And most of the delayed union or nonunion come from unlimited stripping of periosteum and destroying of blood supply during operation [27, 28, 29]. Second, although compression of two fragments can be ensured by a lag screw, it is almost impossible for all multi-fragments to contact 
tightly. And wire had the problem of tension loss or breakage when twisting which limits its strength [13, 30]. Fortunately, there is no need to worry about breakage or weak strength of the Nice knot made by nonabsorbable suture $[13,19]$. As a result, several reasonably arranged Nice knots can provide perfect compression of all fragments which is another well-known important factor for fracture healing.

The total complication ratio of this study was $7.9 \%$ in 101 participants, 5 numbness around the incision, 2 nonunion and 1 refracture post hardware removal. It was lower than most previous studies $[9,7,11,27$, 31]. The damage of periosteum and blood supply during fixation of lag screw might assume the main responsibility for the failures in traditional group. For the plate breakage in Nice knot group, we reviewed the operation record and found that the surgeon turned to fix with suture owing to unsatisfactory result of lag screw and wire, so the soft tissue was already destroyed before Nice knot. This surgical error was confirmed by the surgeon, who performed the revision operation combining an anatomic and a mini plate with auto cancellous bone graft. And consolidation of fracture was confirmed 15 weeks after second surgery. Regarding the refracture, there are several common risk factors: comminuted fracture pattern and bone defects [32, 33], inadequate compression between fractures [32], microfracture occurred during removal of screws or wires [34]. Recently, Tsai et al [35] claimed that female and low BMI were another two risk factors associated with refracture post plate removal for midshaft clavicle fractures. In our study, the female patient suffering from refracture was a slim young woman with a very small bone diameter. Decrease of bone strength due to excessive screw/bone diameter ratio [36] might be the main cause of the refracture, because we used $3.5 \mathrm{~mm}$ diameter lag screws in all cases which might not be suitable for the patient. Smaller diameter lag screw $(2.7 \mathrm{~mm}$ or $2.4 \mathrm{~mm})$ might be better for the very patient to decrease bone loss and reduce risk of refracture.

Skin irritation is another common complication of plate fixation for clavicle fracture. There were totally 12 patients $(11.9 \%)$ in our study complained plate discomfort, and the rate was comparable to the other studies with pre-contoured superior plates $[11,37,38]$. But the removal rate $(46.5 \%)$ was higher than the previous reports $[11,37,38]$, because of the very non-medical factors. As all the fractures in our study were fixed with plates, we did not analyse the difference between two groups.

The strengths of this study are the considerable sample size, including only multi-fragments Robinson type 2B midshaft fractures, using a single plate type and standard post-operative management. The main limitations of the study are its single-center retrospective nature, short follow-up duration and defective follow up data. For 12 months follow-up, only less than $50 \%$ patients come to the outpatient for radiographic examination and questionnaire. And only $75.2 \%$ (76 out of 101) patients showed the definite radiographic consolidation of fracture during whole follow up (arrange from 12 to 40 months). We clinically determined those asymptomatic patients without further radiographic data to have good outcomes with healed clavicle and satisfactory function. On the other hand, lag screw and cerclage wire are different auxiliary reduction-fixation technique, but we failed to analyze them separately because of insufficient cases.

\section{Conclusion}


Though there were no significant differences in functional outcomes, fracture healing time and complications between the two groups, the Nice knots technique did significantly reduce the operation time and simplify the process of fracture reduction, so it might be superior than the traditional methods. In addition, it provided orthopedists more treatment options in fracture reduction.

\section{Abbreviations}

ORIF open reduction and internal fixation; ROM:range of motion; DASH score:The Disabilities of Arm, Shoulder and Hand Score; VAS:visual analog scale; MIPO:minimally invasive plate osteosynthesis; SD:standard deviation

\section{Declarations}

\section{Ethics approval and consent to participate}

This study was approved by the medical ethics review board of Quzhou People's Hospital.

\section{Consent for publication}

Not applicable.

\section{Availability of data and materials}

The datasets used and/or analyzed during the current study are available from the corresponding author on reasonable request.

\section{Competing interests}

The authors declare that they have no competing interests.

\section{Funding}

This work was supported by Zhejiang Province Natural Science Foundation of China [Grant NO. LQ19H060003].

\section{Authors' contributions}

SKH, WW and JKG contributed to the concept, literature search and data collection. SKH, CW contributed to the statistics, data analysis and interpretation. SKH drafted the manuscript. WW, JKG, FXH and CW critically revised the article. All authors read and approved the final manuscript.

\section{Acknowledgements}

None. 


\section{References}

1.Khan LA, Bradnock TJ, Scott C, Robinson CM. Fractures of the clavicle. J Bone Joint Surg Am. 2009;91:447-60.

2.van der Meijden OA, Gaskill TR, Millett PJ. Treatment of clavicle fractures: Current concepts review. J Shoulder Elbow Surg. 2012;21:423-29.

3.Chen W, Zhu Y, Liu S, Hou ZY, Zhang XL, et al. Demographic and socioeconomic factors influencing the incidence of clavicle fractures, a national population-based survey of five hundred and twelve thousand, one hundred and eighty seven individuals. Int Orthop. 2018;42:651-58.

4.Robinson CM. Fractures of the clavicle in the adult. Epidemiology and classification. J Bone Joint Surg Br. 1998;80:476-484.

5.Neer CS 2nd. Nonunion of the clavicle. J Am Med Assoc. 1960;172:1006-11.

6.McKee RC, Whelan DB, Schemitsch EH, McKee MD. Operative versus nonoperative care of displaced midshaft clavicular fractures: a meta-analysis of randomized clinical trials. J Bone Joint Surg Am. 2012;94:675-684.

7.Woltz S, Stegeman SA, Krijnen P, van Dijkman BA, van Thiel TPH, et al. Plate fixation compared with nonoperative treatment for displaced Midshaft clavicular fractures: a multicenter randomized controlled trial. J Bone Joint Surg Am. 2017;99:106-12.

8.Guerra E, Previtali D, Tamborini S, Filardo G, Zaffagnini S, et al. Midshaft clavicle fractures: surgery provides better results as compared with nonoperative treatment: a meta-analysis. Am J Sports Med. 2019;47:3541-3551.

9.Canadian Orthopaedic Trauma S. Nonoperative treatment compared with plate fixation of displaced midshaft clavicular fractures. A multicenter, randomized clinical trial. J Bone Joint Surg Am. 2007;89:110 .

10.Robinson CM, Goudie EB, Murray IR, Jenkins PJ, Ahktar MA, et al. Open reduction and plate fixation versus nonoperative treatment for displaced midshaft clavicular fractures: a multicenter, randomized, controlled trial. J Bone Joint Surg Am. 2013;95:1576-84.

11.Ranalletta M, Rossi LA, Bongiovanni SL, Tanoira I, Piuzzi NS, et al. Surgical treatment of displaced midshaft clavicular fractures with precontoured plates. J Shoulder Elb Surg. 2015;24:1036-40.

12.Zlowodzki M, Zelle BA, Cole PA, Jeray K, McKee MD, Evidence-Based Orthopaedic Trauma Working Group. Treatment of acute midshaft clavicle fractures: systematic review of 2144 fractures: on behalf of the Evidence-Based Orthopaedic Trauma Working Group. J Orthop Trauma. 2005;19:504-7. 
13.Boileau P, Alami G, Rumian A, Schwartz DG, Trojani C, et al. The doubled-suture nice knot. Orthopedics. 2017;40:e382-e386.

14.Phadnis J, Watts AC. Tension band suture fixation for olecranon fractures. Shoulder Elbow. 2017;9:299-303.

15.Gilmore JH, Clayton-Smith ZJ, Aguilar M, Pneumaticos SG, Giannoudis PV. Reconstruction techniques and clinical results of patellar tendon ruptures: evidence today. Knee. 2015;22:148-55.

16. Hudak PL, Amadio PC, Bombardier C. Development of an upper extremity outcome measure: The DASH (disabilities of the arm, shoulder and hand) [corrected]. The Upper Extremity Collaborative Group (UECG). Am J Ind Med. 1996;29:602-8.

17. Hill JM, McGuire MH, Crosby LA. Closed treatment of displaced middle-third fractures of the clavicle gives poor results. J Bone Joint Surg Br. 1997;79:537-39.

18.McKee RC, Whelan DB, Schemitsch EH, McKee MD. Operative versus nonoperative care of displaced midshaft clavicular fractures: A meta-analysis of randomized clinical trials. J Bone Joint Surg Am. 2012;94:675-84.

19.Boileau P, Pennington SD, Alami G. Proximal humeral fractures in younger patients: fixation techniques and arthroplasty. J Shoulder Elbow Surg. 2011;20:S47-60.

20.Wähnert D, Lenz M, Schlegel U, Perren S, Windolf M. Cerclage handling for improved fracture treatment. A biomechanical study on the twisting procedure. Acta Chir Orthop Traumatol Cech. 2011;78:208-14.

21.Sohn HS, Kim WJ, Shon MS. Comparison between open plating versus minimally invasive plate osteosynthesis for acute displaced clavicular shaft fractures. Injury. 2015;46:1577-1584.

22.Kim JY, Yoo BC, Yoon JP, Kang SJ, Chung SW. A comparison of clinical and radiological outcomes of minimally invasive and conventional plate osteosynthesis for midshaft clavicle fractures. Orthopedics. 2018;41:e649-e654.

23.Reisch T, Camenzind RS, Fuhrer R, Riede U, Helmy N. The first 100 patients treated with a new anatomical pre-contoured locking plate for clavicular midshaft fractures. BMC Musculoskelet Disord. 2019;20:4.

24.Jiang H, Qu W. Operative treatment of clavicle midshaft fractures using a locking compression plate: comparison between mini-invasive plate osteosynthesis (MIPPO) technique and conventional open reduction. Orthop Traumatol Surg Res. 2012;98:666-71.

25. You JM, Wu YS, Wang Y. Comparison of postoperative numbness and patient satisfaction using minimally invasive plate osteosynthesis or open plating for acute displaced clavicular shaft 
fractures. Int J Surg. 2018;56:21-25.

26.Zehir S, Sahin E, Songür M, Altunkiliç T, Özdemir G. Minimal invasive percutaneous plate osteosynthesis (MIPPO) vs. open plating in superior plating of midshaft clavicle fractures. Acta Orthop Belg. 2018;84:491-496.

27.Hulsmans MH, van Heijl M, Houwert RM, Hammacher ER, Meylaerts SA, et al. High irritation and removal rates after plate or nail fixation in patients with displaced midshaft clavicle fractures. Clin Orthop Relat Res. 2017;475:532-39.

28.Wilson DJ, Scully WF, Min KS, Harmon TA, Eichinger JK, et al. Biomechanical analysis of intramedullary vs. superior plate fixation of transverse midshaft clavicle fractures. J Shoulder Elbow Surg. 2016;25:949-53.

29.Tarng YW, Yang SW, Fang YP, Hsu CJ. Surgical management of uncomplicated midshaft clavicle fractures: A comparison between titanium elastic nails and small reconstruction plates. J Shoulder Elbow Surg. 2012;21:732-40.

30.Steinberg EL, Shavit R. Braided cerclage wires: a biomechanical study. Injury. 2011;42:347-51.

31.Böstman O, Manninen M, Pihlajamäki H. Complications of plate fixation in fresh displaced midclavicular fractures. J Trauma. 1997;43:778-83.

32.Deluca PA, Lindsey RW, Ruwe PA. Refracture of bones of the forearm after the removal of compression plates. J Bone Joint Surg Am. 1988;70:1372-6.

33.Yao CK, Lin KC, Tarng YW, Chang WN, Renn JH. Removal of forearm plate leads to a high risk of refracture: decision regarding implant removal after fixation of the forearm and analysis of risk factors of refracture. Arch Orthop Trauma Surg. 2014;134:1691-7.

34.Rosson JW, Petley GW, Shearer JR. Bone structure after removal of internal fixation plates. J Bone Joint Surg Br. 1991;73:65-7.

35.Tsai SW, Ma HH, Hsu FW, Chou TA, Chen KH, et al. Risk factors for refracture after plate removal for midshaft clavicle fracture after bone union. J Orthop Surg Res. 2019;14:457.

36.Edgerton BC, An KN, Morrey BF. Torsional strength reduction due to cortical defects in bone. J Orthop Res. 1990;8:851-5.

37.Campochiaro G, Tsatsis C, Gazzotti G, Rebuzzi M, Catani F. Displaced midshaft clavicular fractures: surgical treatment with a pre-contoured angular stability plate. Musculoskelet Surg. 2012;96 Suppl 1:S216. 
38.VanBeek C, Boselli KJ, Cadet ER, Ahmad CS, Levine WN. Precontoured plating of clavicle fractures: decreased hardware-related complications? Clin Orthop Relat Res. 2011;469:3337-43.

\section{Tables}

Table 1 Patient characteristic and surgical data

\begin{tabular}{llll}
\hline & $\begin{array}{l}\text { Nice knot group } \\
(\mathrm{n}=52)\end{array}$ & $\begin{array}{l}\text { Traditional group } \\
(\mathrm{n}=49)\end{array}$ & $\mathrm{P}$ \\
\hline Age (years) & $50.8 \pm 11.2(24-69)$ & $50.9 \pm 12.2(20-71)$ & 0.775 \\
\hline Sex, male/female & $34 / 18$ & $31 / 18$ & 0.824 \\
\hline Left/right shoulder & $25 / 27$ & $28 / 21$ & 0.362 \\
\hline Type 2B2 & $39(75.0 \%)$ & $28(57.1 \%)$ & 0.058 \\
\hline Mechanism of injury & & & 0.947 \\
\hline Traffic accident & $31(59.6 \%)$ & $27(55.1 \%)$ & \\
\hline Fall flat & $17(32.7 \%)$ & $18(36.7 \%)$ & \\
\hline Fall from height & $3(5.8 \%)$ & $3(6.1 \%)$ & \\
\hline Sports & $1(1.9 \%)$ & $1(2.0 \%)$ & 0.267 \\
\hline Injury-to-surgery (days) & $3.3 \pm 3.5(1-16)$ & $4.1 \pm 4.1(0-22)$ & 0.964 \\
\hline Plate bending & $14(26.9 \%)$ & $13(26.5 \%)$ & 0.002 \\
\hline Operation time (min) & $78.6 \pm 19.0(40-135)$ & $94.4 \pm 29.9(45-165)$ & 0.911 \\
\hline Follow-up (months) & $25.8 \pm 7.9(13-40)$ & $25.9 \pm 8.4(12-40)$ & 0.633 \\
\hline Implant removal & $23(44.2 \%)$ & $24(49.0 \%)$ & 0.698 \\
\hline Interval between fixation and removal (months) & $15.0 \pm 3.0(11-22)$ & $15.3 \pm 3.9(12-24)$ & \\
\hline Data are expres & & \\
\hline
\end{tabular}

Data are expressed as mean \pm standard deviation (range) or $n$ (\%); Type 2B2 Robinson type 2B clavicle fracture 
Table 2 Outcomes according to treatment groups

\begin{tabular}{llll}
\hline & Nice knot group $(\mathrm{n}=52)$ & Traditional group $(\mathrm{n}=49)$ & $\mathrm{P}$ \\
\hline Healing time (weeks) & $\begin{array}{l}13.14 \pm 3.72(6.9-19.1) \\
(\mathrm{n}=21)\end{array}$ & $\begin{array}{l}14.43 \pm 2.98(8.4-20.6) \\
(\mathrm{n}=20)\end{array}$ & 0.228 \\
\hline DASH score & $\begin{array}{l}5.50 \pm 1.79(1.72-9.26) \\
(\mathrm{n}=23)\end{array}$ & $\begin{array}{l}5.61 \pm 1.93(1.67-9.16) \\
(\mathrm{n}=20)\end{array}$ & 0.846 \\
\hline VAS score & $0.26 \pm 0.45(0-1)$ & $0.35 \pm 0.49(0-1)$ & 0.530 \\
& $(\mathrm{n}=23)$ & $(\mathrm{n}=20)$ & \\
\hline Final satisfaction & $51(98.1 \%)$ & $47(95.9 \%)$ & 0.610 \\
\hline All complications & $3(5.8 \%)$ & $5(10.2 \%)$ & 0.408 \\
\hline Wound complications & $0(0 \%)$ & $0(0 \%)$ & $/$ \\
\hline Skin numbness & $2(4.1 \%)$ & $3(6.1 \%)$ & 0.672 \\
\hline Major complication & $1(1.7 \%)$ & $2(4.1 \%)$ & 0.610 \\
\hline Nonunion with Implant failure & $1(1.7 \%)$ & $1(2.0 \%)$ & 1.000 \\
\hline Nonunion without Implant failure & $0(0 \%)$ & $0(0 \%)$ & $/$ \\
\hline Refracture & $0(0 \%)$ & $1(2.0 \%)$ & 0.485 \\
\hline Revision surgery & $1(1.7 \%)$ & $0(0 \%)$ & 1.000 \\
\hline
\end{tabular}

Data are expressed as mean \pm standard deviation (range) or $\mathrm{n}(\%)$

\section{Figures}
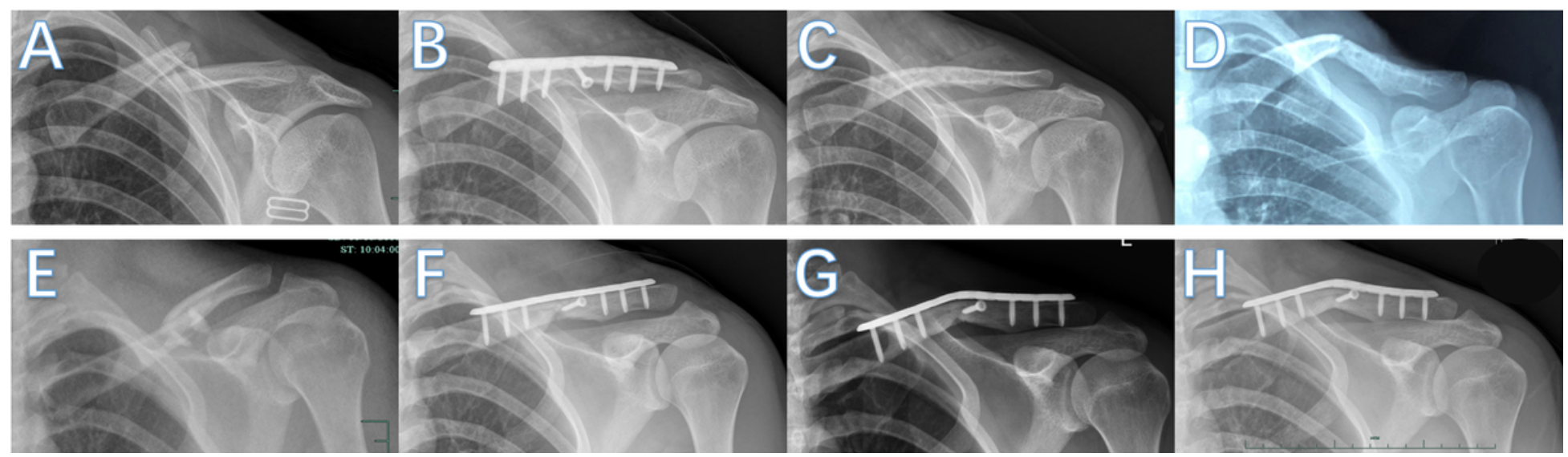

Figure 1 


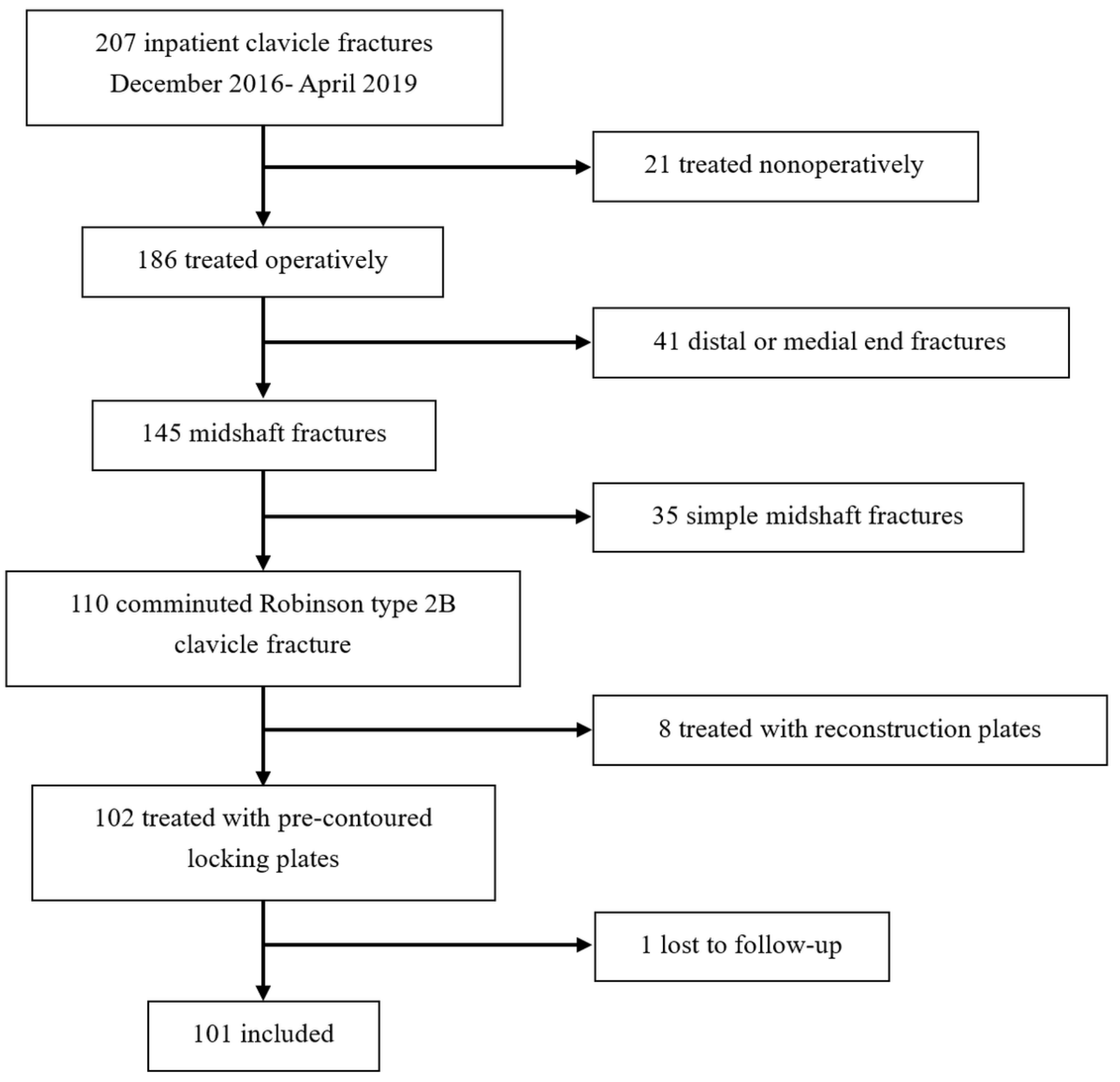

Figure 2

Flow chart of patients screening 

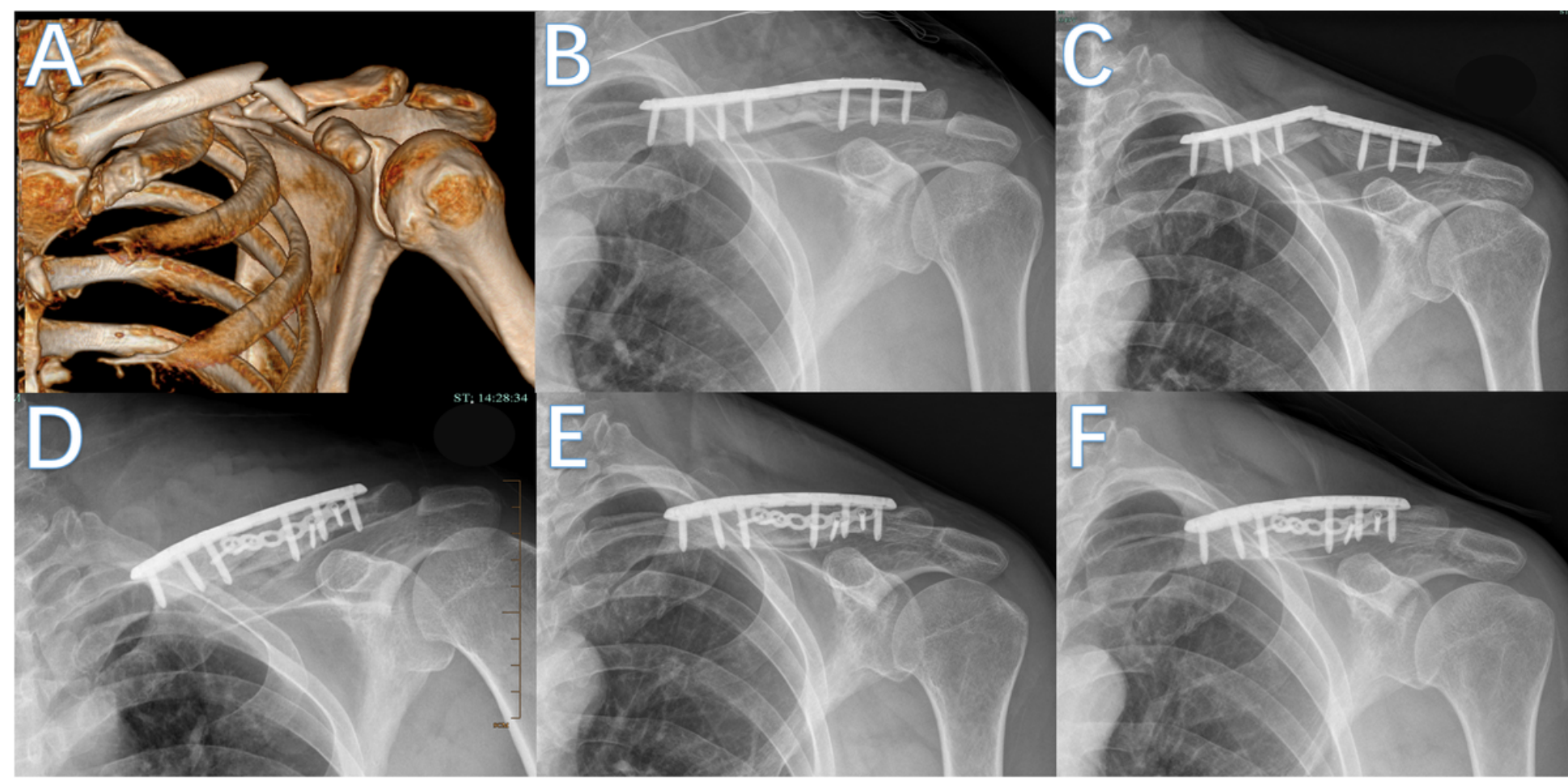

\section{Figure 3}
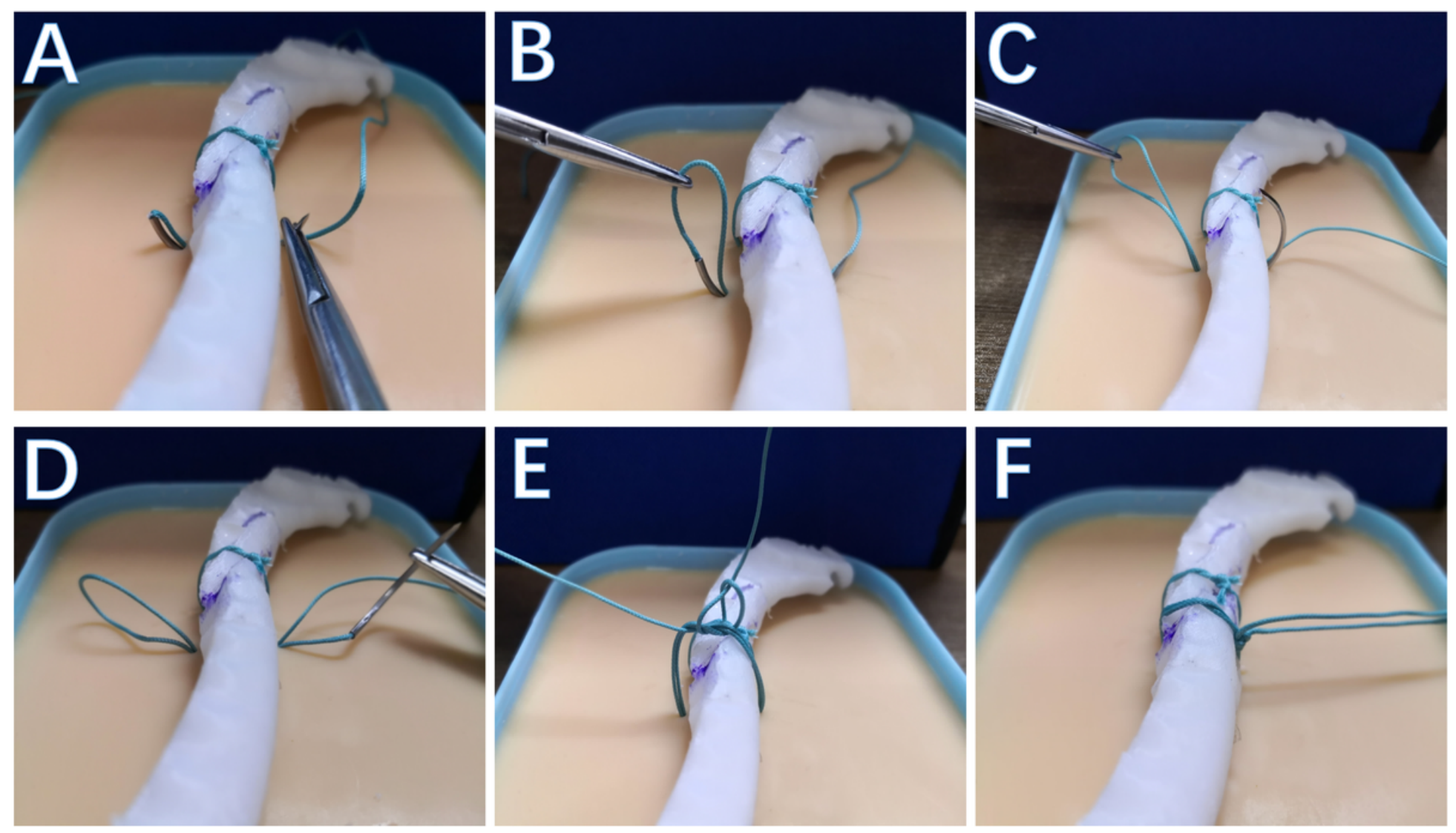

\section{Figure 4}

The key steps of the Nice knot introduced by needle tail (demonstrated with a 3D model of clavicle and No. 5 Ethibond). A Needle tail through the tissue around model. B-D Draw out the suture and then return 
the needle to get a doubled-over suture. E Make a Nice knot with single free limb passing through the loop. F The knot is slid down by pulling the 2 free limbs apart.
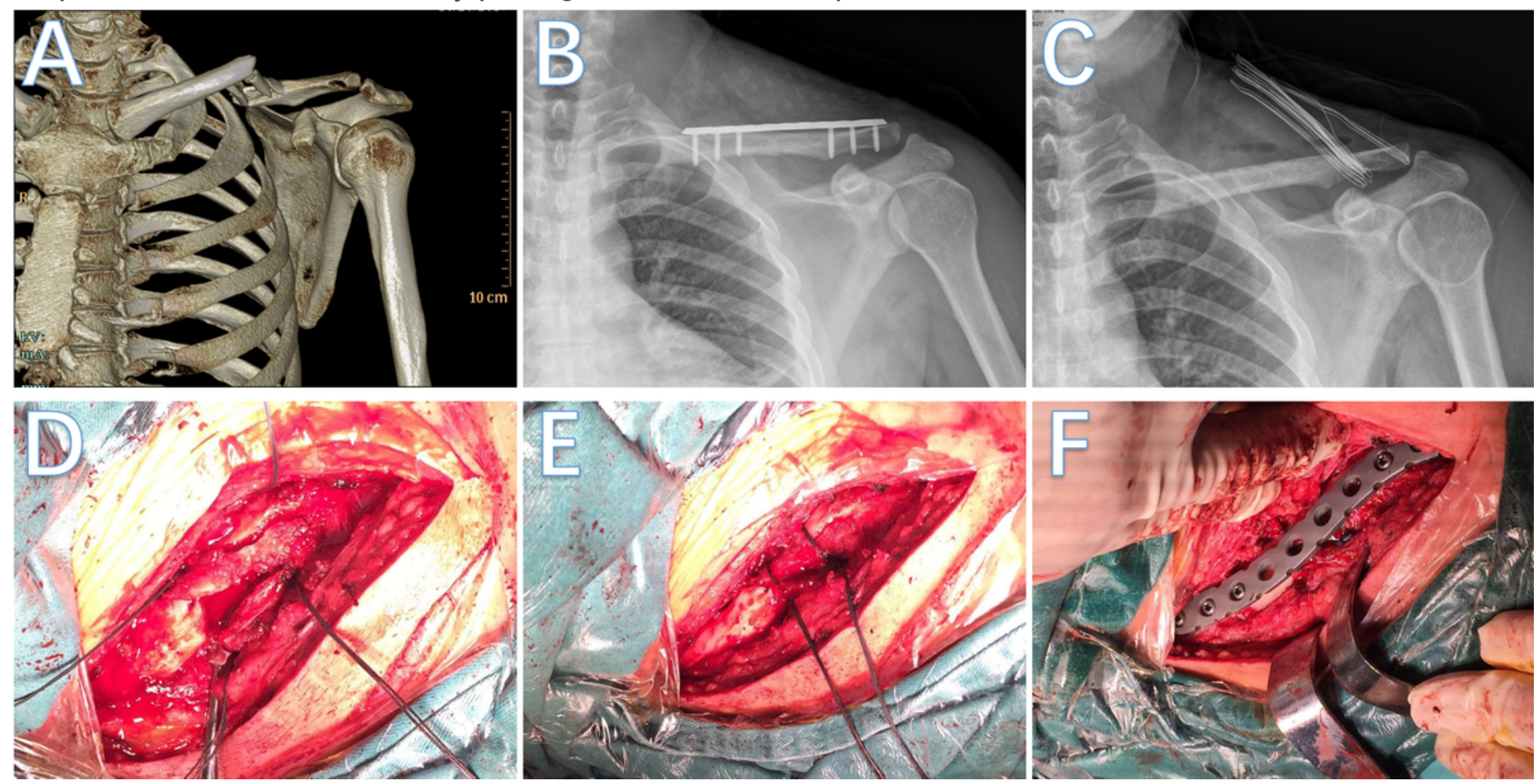

Figure 5

A 34 years old male patient with Type 2B2 left clavicle fracture in the Nice knot group. A Pre-operative CT scan. B Post-operative X-ray. C X-ray after removal of implant at 14 months. D The pre-reduced fracture and doubled-over suture induced by needle tail. E Reduction and temporarily fixation of the fracture by two Nice knots. F Bridged with a pre-contoured locking plate and screws. 